DOI: 10.20472/IAC.2018.042.002

\author{
TAQADUS BASHIR \\ BAHRIA UNIVERSITY, ISLAMABAD CAMPUS, Pakistan
}

TAIMOOR HASSAN

University of Gujrat, Pakistan

\title{
INVESTOR SOPHISTICATION: INTRUSION OF BEHAVIORAL BIASES IN INVESTMENT DECISIONS
}

\begin{abstract}
:
Economics and conventional investment theory assumes that people are rational while markets are efficient, but people often think and act irrationally, and financial markets rarely follow textbook models of efficiency. Whereas behavioral finance uses knowledge from psychological studies in context of decision making in comparison to the so called predictable models popular in standard finance. Most oftenly investor behavior diverges from logics and rationality as investors are victim of numerous behavioral errors that intervene while they form up investment decision. Decison making is complicated due to the intervention of emotional attachments $\&$ avoidances, cognitive errors, and personality traits of decision makers. In developing country like Pakistan where the environment is unstable due to factors like security threats, terrorism, inflation, energy crises and are affecting the thinking pattern of people and the ratio of educated entrepreneur is very less, decisions are based on gut feelings, there is a need to study the impact of self-control, self-attribution along with cognitive dissonance and confirmation bias on investment decision and the current aimed to do so. The present study collected primary data through questionnaire from stock and bond investors. Significant positive relationship is found between the study biases and their impact on investment decisions of investors. Almost all the subjects were found to be the victims of confirmation bias, self-control bias, self-attribution $\&$ cognitive dissonance bias. Financial advisors are recommended to be first trained and then consulted for the detection $\&$ moderation of these biases before making investment decisions.
\end{abstract}

\section{Keywords:}

Behavioral Finance, confirmation bias, self-control bias, self-attribution, cognitive dissonance bias, financial advisors, investment decisions.

JEL Classification: G02, G11, D23 